Boston University School of Law

Scholarly Commons at Boston University School of Law

Faculty Scholarship

2020

\title{
Federalism Complicates the Response to the COVID-19 Health and Economic Crisis: What Can Be Done?
}

Nicole Huberfeld

Boston University School of Public Health; Boston University School of Law

Sarah Gordon

David K. Jones

Follow this and additional works at: https://scholarship.law.bu.edu/faculty_scholarship

Part of the Health Law and Policy Commons

\section{Recommended Citation}

Nicole Huberfeld, Sarah Gordon \& David K. Jones, Federalism Complicates the Response to the COVID-19 Health and Economic Crisis: What Can Be Done? , in 45 Journal of Health Politics, Policy and Law 951 (2020).

Available at: https://scholarship.law.bu.edu/faculty_scholarship/1003

This Article is brought to you for free and open access by Scholarly Commons at Boston University School of Law. It has been accepted for inclusion in Faculty Scholarship by an authorized administrator of Scholarly Commons at Boston University School of Law. For more information, please contact lawlessa@bu.edu. 


\title{
Federalism Complicates the Response to the COVID-19 Health and Economic Crisis: What Can Be Done?
}

\author{
Nicole Huberfeld \\ Sarah H. Gordon \\ David K. Jones \\ Boston University
}

\begin{abstract}
Federalism has complicated the U.S. response to the novel coronavirus. States' actions to address the pandemic have varied widely, and federal and state officials have provided conflicting messages. This fragmented approach surely cost time and lives. Federalism will shape the long-term health and economic impacts of COVID-19, including plans for the future, for at least two reasons: First, federalism exacerbates inequities, as some states have a history of under-investing in social programs, especially in certain communities. Second, many of the states with the deepest needs are poorly equipped to respond to emergencies due to low taxes and distrust of government, leading to inadequate infrastructure. These dynamics are not new, but they have been laid bare by this crisis. What can policymakers do to address the inequities in health and economic outcomes that federalism intensifies? The first section of this paper offers a case study, using the Mississippi Delta to illustrate the role of federalism in perpetuating the connection between place, health, and economics. The second section examines challenges that safety net programs will face moving beyond the acute phase of COVID-19. Our final section explores near-, middle-, and long-term policy options to mitigate federalism's harmful side effects.
\end{abstract}

Keywords Affordable Care Act, federalism, Medicaid, health reform, coronavirus, COVID-19, state health policy

Federalism - the formal division of power between a central government and sovereign states-

has complicated the U.S. response to the novel coronavirus. States varied in establishing physical distancing measures, administering testing, and issuing crucial equipment such as personal protective equipment and ventilators. The President, governors, and other leaders provided conflicting messages about public safety. This fragmented and disjointed response undoubtedly cost time and lives.

Federalism will play a profound role in shaping the long-term health and economic impacts of COVID-19, including our nation's ability to mount a response and plan for the future. Forthcoming in an issue of Journal of Health Politics, Policy and Law. Journal of Health Politics, Policy and Law is published by Duke University Press. DOI: 10.1215/03616878-8641493 
This is true in two ways. First, low-income as well as racial and ethnic minority populations are at greater risk of being exposed to the virus, more likely to have chronic conditions that increase the risk of dying if they are infected, and least able to weather financially the economic recession coronavirus triggered (Villarosa 2020; Zephyrin et al. 2020). This is true nationwide, but federalism exacerbates these inequities, as some states have a particularly deep history of underinvesting in social programs, especially in certain communities.

Second, many states with the deepest needs are also least equipped to respond due to a culture of low taxes and distrust of government. This often means an inadequate infrastructure of funds, people, and institutions to implement an emergency response.

These dynamics are not new, but they have been laid bare by the current crisis. The emergence of this virus during an election year adds another intergovernmental wrinkle, particularly given that many of the key presidential battleground states are now led by Democratic governors, which has motivated the President to undermine their pandemic efforts. It is harder for voters to know whom to hold accountable as leaders at both levels engage in blameshifting and credit-claiming. It is not yet clear how COVID-19 is altering public opinions about health reform. Solidarity often emerges from national emergencies, but the politics of selfreliance and liberty are likely to reemerge as the acute phase of this crisis recedes.

In theory, states can act as laboratories of learning, with the best ideas spreading horizontally to other states and vertically to the federal government. However, the political science literature on the diffusion of policies across states suggests that this is often actually ideological mimicking or political learning rather than evidence-based learning based on objective reporting of policy results (Shipan and Volden 2008).

Forthcoming in Journal of Health Politics, Policy and Law. DOI: 10.1215/03616878-8641493 
What can policymakers do to address the inequities in health and economic outcomes that federalism intensifies? The first section of this paper uses the Mississippi Delta as a case study to illustrate the role of federalism in perpetuating the deep connection between place, health, and economics. The second section examines challenges safety net programs will face as we move beyond the acute phase of COVID-19. Our final section explores near-, middle-, and long-term policy options to mitigate federalism's harmful side effects.

\section{The Mississippi Delta}

It is too early to measure fully the health impact of COVID-19. But as more time passes, the map of per-capita infection rates looks increasingly like most other maps of health outcomes in the U.S., with the hardest-hit regions being in the South, diverse neighborhoods in northern urban cores, and poor, rural counties across the country. For example, as of April $9,40 \%$ of people in Michigan who died of novel coronavirus were Black, even though only $14 \%$ of the state is Black, driven primarily by infection rates and complications in Detroit (Villarosa 2020). Similar dynamics are playing out in places like Massachusetts, which, despite being the healthiest state by some measures, still demonstrates that race, class, and health outcomes are linked. For example, Chelsea is a largely low-income, non-White town that quickly became a COVID-19 hotspot due to the number of people working hourly wage jobs and living in cramped housing. The Mississippi Delta offers a powerful case study by illuminating intersections of race, class, law, and policy that exist nationwide and that structure responses to and the impacts of the pandemic.

\section{Social Determinants of Health}

Forthcoming in Journal of Health Politics, Policy and Law. DOI: 10.1215/03616878-8641493 
Each of the social determinants of health that puts Mississippians at greater risk for being infected by novel coronavirus also exacerbates the challenge of living with the pandemic's economic fallout. Mississippians suffer in greater numbers from preventable illnesses such as asthma, hypertension, and diabetes - diseases that worsen COVID-19 outcomes - yet lack adequate access to high-quality health care. For example, more than $43 \%$ of adults in Coahoma County (the heart of the Delta) are obese, and 20\% of Black newborns weigh less than 2,500 grams (Jones 2017). Access to health care is limited, with more than half (59\%) of Mississippians living in a Health Professional Shortage Area and fewer than half receiving insurance through an employer, whereas the national average is 57\% (KFF 2020a). The statewide uninsured rate of $11.9 \%$ in 2018 was the sixth highest in the nation (AHR 2019). At least $30 \%$ of the population in nine Delta counties lacks food security (PHI 2018). Residents of the Delta also face barriers to being physically active, including unsafe housing, few parks, and high crime rates. Approximately 1 in 5 households experiences a severe housing problem such as inadequate indoor plumbing (PHI 2016a). The state ranks eighth in eviction rates (Hensley 2018).

The cost of living is low, but the median household income in most Delta counties is around $\$ 30,000$ per year, far below the national median income of $\$ 62,000$ (Guzman 2019; PHI 2016b). Retail cashier is the most common job, with 42,000 cashiers across the state earning an average salary of $\$ 19,620$ (Wolfe 2019). Many Delta counties entered the COVID-19 crisis with unemployment rates of $7.8 \%$ to $11.1 \%$, dramatically higher than the national rate of less than $4 \%$ before the pandemic (MSDES 2020). The number of unemployment claims in Mississippi increased by $1700 \%$ (from 2,026 to 36,465) over a two-week period in March 2020 as the 
governor ordered a shut-down of non-essential businesses, yet the state provides meager safety net programs (Wolfe 2020a).

\section{The Role of State Policy}

Federalism creates and perpetuates these inequities in many ways. Structural racism has an intensely geographic facet; for example, more than $60 \%$ of people in most Delta counties are Black, compared to $37.8 \%$ of Mississippians and 12.3\% of Americans (PHI 2016c; U.S. Census Bureau 2019). This racial distribution is rooted in slavery and legal protections for states' rights in the Constitution, which carried through Reconstruction and Jim Crow (Jones 2019). The level of support among White people for safety net programs today is closely linked to the share of that county's population in slavery in 1860 (Acharya, Blackwell, and Sen 2018).

State policies often exacerbate poverty and inequity. Mississippi has not expanded Medicaid eligibility under the ACA and has one of the lowest eligibility thresholds in the nation at $26 \%$ of the federal poverty level (MS Division of Medicaid 2019). Consequently, half of Mississippi's rural hospitals are at risk of closure because they are overwhelmed by uncompensated care (Campbell 2019).

Mississippi is one of 31 states that has not enacted a minimum wage higher than the federal level of \$7.25 per hour (Wolfe 2019). Savings and wealth cannot be built on such an income, making a pandemic and resulting recession more devastating for low-income workers. Mississippi also has more payday lenders per capita than any other state, largely because it has fewer regulations (MS Center for Justice 2019).

Approximately one fifth of Mississippians receive food stamps through the Supplemental Nutrition Assistance Program (SNAP), the highest proportion of any state. The average SNAP 
payment is $\$ 115$ per month, or $\$ 1.26$ per person per meal (Nchako and Cai 2020). The legislature has taken a particularly aggressive approach to limiting the ability of "able-bodied" working adults to receive SNAP benefits, in part because of concerns about fraud, waste, and abuse (MS HB 1090 2017). Ironically, many of the state leaders responsible for investigating fraud in SNAP and other safety net programs have been arrested for embezzling funds (Wolfe 2020b). Federalism puts social program beneficiaries at the mercy of the integrity, efficiency, and judgment of state leaders, even when national standards govern such programs.

Each state policy choice helps to explain why people in the Mississippi Delta are particularly vulnerable to the health and economic shock of COVID-19. History teaches that recessions are deepest and last longest in places that are already struggling (Ganucheau 2018). The developing health and economic crisis in the Mississippi Delta-and across other vulnerable communities throughout the U.S.-is the result of centuries of disparities perpetuated by federalism.

\section{The Health Care Safety Net and COVID-19}

The pandemic will have acute and long-term effects on state budgets and therefore state financing of safety net programs, particularly given that the vast majority of state governments are required to balance their budgets. While the federal government can respond to the coronavirus pandemic by deficit spending to infuse new dollars into the economy, states must find the funding by repurposing money from existing budgets or relying on federal government assistance.

States are largely responsible for coordinating and financing pandemic response efforts because of the federalist structure of the American public health system. States have been the 
primary payer for the majority of the response, including purchasing personal protective equipment, establishing sites where individuals with coronavirus can quarantine safely, increasing charity care payments to hospitals, and tracking and tracing of coronavirus cases. The federal government has limited authority to run a centralized pandemic response yet can help with money and coordination. But, in the case of coronavirus, the federal government has unevenly assisted states. The lack of federal coordination and funding leaves states scrambling to pay for an emergency that far outpaces what they could have budgeted for, despite the fact that the majority of state budgets had been stable in 2019 (Pew 2020). The long-term implications of the economic downturn on state economies could cost states an additional $\$ 360$ billion (McNicol, Leachman, and Marshall 2020). Studies estimate that a one percentage point increase in the unemployment rate is associated with a $3 \%$ to $5 \%$ decrease in tax revenue per capita, or a $\$ 45$ billion decrease in states’ budgets (Fiedler and Powell 2020).

Economic instability highlights the problems with a fragmented health care financing system. For a majority of Americans, health insurance is linked to employment. Fluctuating incomes may exacerbate transitions and gaps in coverage between Medicaid, Marketplace, and other forms of insurance coverage. Many of the record-breaking number of newly unemployed individuals lost insurance coverage just at the time when access to health care is critical. Prior research has shown that even short disruptions in health insurance can have deleterious effects on health. States are expected to absorb these newly uninsured individuals, but their unemployment and Medicaid agencies will struggle to keep up. In addition, the Trump administration's decision not to open enrollment on the federal Marketplace means that individuals can enroll in subsidized coverage through the federal exchange only if they qualify for a special enrollment period (Claxton et al. 2019).

Forthcoming in Journal of Health Politics, Policy and Law. DOI: 10.1215/03616878-8641493 
As unemployment applications skyrocket into the tens of millions, applications for Medicaid coverage will follow. Medicaid is the backbone of the health care financing system and plays a critical role during economic downturns. As a countercyclical program, enrollment in Medicaid increases when the economy declines, but Medicaid's countercyclical effects will be severely limited in nonexpansion states as they respond to coronavirus and the recession it triggered. Medicaid's federal-state shared financing structure means the program can be responsive in a crisis, as federal funds match state Medicaid spending with no cap. In 2009, following the Great Recession, total Medicaid spending growth averaged 7.9\% nationally, attributable almost entirely to increased enrollment (Smith et al. 2009).

The economic recession related to coronavirus is distinct from prior downturns in the uniformity of the loss of employment across the country and across employment sectors, with a particularly acute effect in retail, food services, and agriculture-industries that are less likely to offer insurance as an employment benefit. The resulting budgetary impact on Medicaid and other safety net programs is likely to be much larger than prior recessions because so many low wage workers are affected at one time. In addition, coronavirus is constraining the use of high-volume medical services such as primary care, behavioral health, and long-term care as well as safety net facilities such as community health centers and public hospitals, all of which have decreased revenue. Avoidance of in-person and non-emergency care during the pandemic will place additional long-term pressures on health care providers who serve Medicaid patients and thus additional pressures on states to support them.

Despite open-ended federal matching, states face budgetary challenges during economic downturns covering their share of Medicaid costs, which can result in reductions in eligibility, covered benefits, or provider rates. When states experience a Medicaid enrollment surge, they 
often rely on a few typical emergency tools. These include increasing taxes, decreasing spending on other state programs, and requesting more federal assistance.

Coronavirus offers a poignant example for why capping Medicaid enrollment or implementing block grants with finite Medicaid funding would be disastrous policy. If Medicaid were block granted as proposed in CMS's Healthy Adult Opportunity policy (and multiple Affordable Care Act repeal and replace bills), states would face far more dire fiscal consequences than they do now. Budget and enrollment caps could lead states to deny needed coronavirus services and result in increased uncompensated care, digging a deeper hole that would require more federal assistance. In addition, many states have obtained waivers to require certain Medicaid enrollees to satisfy criteria for working to maintain coverage. Such "work requirements" are punitive and especially irrational in times of economic distress, as employment options are limited due to forces beyond enrollees' control. All states have suspended their work requirements during the pandemic.

Two recent coronavirus response laws directed federal money to states through Medicaid: the Families First Coronavirus Response Act and the CARES Act. The Families First Act included an increase in the federal match by 6.2 percentage points, but this bump only lasts the duration of the public health emergency. These acts greenlighted an array of short-term changes to Medicaid programs. For example, several states have received approval for State Plan Amendments to cover coronavirus testing for the uninsured with Medicaid and to reduce the administrative burden of Medicaid enrollment. Nearly all states have received HHS approval to expand access to telehealth services and increase provider payments for telehealth visits. States also have obtained 1135 public health emergency waivers that reduce regulatory requirements to enable care across state lines and in unlicensed facilities (KFF 2020b). The Families First Act 
also authorizes states to modify their Supplemental Nutrition Assistance Programs (SNAP); all states have opted to provide additional emergency benefits to certain households up to the maximum benefit limit, and the majority of states limited reporting requirements to help maintain participation (CBPP 2020).

While these changes are laudable and necessary, they are narrow in scope and duration and are insufficient to address long-term impacts of the coronavirus pandemic. Quickly granting 1135 public health emergency waivers or easing paperwork for safety net programs does not create a path to longer term coverage, and telehealth is just a tool (albeit an important one in this situation).

\section{Beyond the Pandemic}

Looking forward, the nation will grapple with mitigating the effects of novel coronavirus and preparing better for the next emergency, aims that must include addressing health inequities perpetuated by federalism as a health policy choice. Larger-scale changes are necessary to address long-term challenges. In this part, we consider near-, middle-, and long-term solutions, focusing on stronger federal baselines to achieve more universal social programs.

\section{Short Term}

The stimulus bills' payment for coronavirus testing through Medicaid is a small step that may alleviate some of the fear that would prevent uninsured people from seeking care, but it barely reduces the substantial financial strain that looms from the possibility of a hospital stay that could end up in the expensive ICU setting. In other words, the uninsured are particularly vulnerable during this outbreak and will remain so in its wake. 
In contrast to the federal stimulus funds offering temporary state budget relief, Medicaid expansion is a more durable option with long-lasting health and economic benefits demonstrated by more than 400 studies (Guth, Garfield, and Rudowitz 2020). States that have not expanded Medicaid eligibility are fighting the pandemic with a partial toolbox. Medicaid offers comprehensive coverage at no or little cost to beneficiaries, making it particularly beneficial for low-income populations in times of crisis. The program is uniquely positioned to respond to the pandemic and associated health disparities. Medicaid providers are often deeply embedded within low-income communities, offering a trusted source of care for hard-to-reach populations that may be distrustful of the medical system. Additionally, Medicaid operates within existing state systems and requires no new infrastructure or specific oversight.

For fourteen states, expanding Medicaid would supply a federal match rate of $90 \%$ for newly eligible adults and quickly address a coverage gap that harms the health and economic security of 2.3 million individuals. Medicaid expansion was a financially attractive deal before novel coronavirus but now offers a lifeline to states hit hardest by the coronavirus recession. Coronavirus may change states' calculations as the fiscal burden of the recession becomes clear and their populations turn to the government for help. The Trump administration has ignored Medicaid expansion in crafting responses to the pandemic, but the option remains.

The American Recovery and Reinvestment Act of 2009 (ARRA) provides a model for the next round of federal stimulus and recovery legislation, as the ARRA enhanced the federal match for Medicaid for three years and provided a calculation for automatic increases with high unemployment in a state (Public Law 111-5, sec. 5001). The Families First Act and the CARES Act address the immediate emergency and require that states perform for the increased match by meeting certain maintenance of effort requirements such as stable Medicaid eligibility. But, by 
most accounts, the recession will extend far beyond the pandemic. States will continue to clamor for federal funds, and a straightforward legislative response to health and economic needs would reduce state budgetary strain and individual financial insecurity. Congress should extend the Families First $6.2 \%$ increase in the federal match for several years.

Further, Congress should extend the increased match to the Medicaid expansion population, raising the match from $90 \%$ to $96.2 \%$, a choice that the first two stimulus bills bypassed. Extending the increased federal match would make it so expansion states do not suffer for having made that choice, as many of the newly uninsured will fit the expansion category of eligibility. This match could be enough to incentivize opt-out states to reconsider. States and the Trump administration can also strengthen the safety net and protect vulnerable populations by halting waivers that eliminate retroactive eligibility in Medicaid, seek work requirements (which have been adjudicated unlawful as authorized), or seek block grants.

\section{Middle Distance}

Public health experts predict that novel coronavirus will become a disease with recurring outbreaks like the flu but more contagious and with higher mortality. Until a vaccine or other medications are developed, the same ZIP code dynamics will play out, and low-income individuals and people of color will continue to suffer more. One way to address this concern beyond the novel coronavirus pandemic could be to amend the Medicaid Act so that the FMAP increases with high unemployment, like the ARRA. Changing Medicaid financing so it can adapt to unemployment without dependence on emergency declarations would strengthen the federal floor, which could protect state budgets and improve equity in social determinants of health. This option would work best with full Medicaid expansion.

Forthcoming in Journal of Health Politics, Policy and Law. DOI: 10.1215/03616878-8641493 
HHS also should reinstate the Obama-era rules for determining sufficient payment to Medicaid providers. Medicaid pays notoriously low rates, so determining "sufficient" payment has been a fraught question, but adequate payment is often sacrificed with economic downturns - the very moment that more Medicaid providers are needed. Similarly, increasing Medicaid provider rates—as the ACA did temporarily—could help to ensure that Medicaid eligibility is not a door to nowhere. This would particularly help hospitals that serve poor communities and rural areas, thereby addressing wide disparities in hospital resources.

\section{Long Term}

What are the principles that should serve as a foundation for considering more fundamental and structural change?

First, health insurance coverage and access to basic medical care must be universal and equitable. This does not necessarily require that everyone be in a single program but does suggest a strong federal role that does not leave coverage at the mercy of state budgets. This is one advantage that the Medicare program and its beneficiaries have always enjoyed. The strongest federal approach, single-payer federal health insurance or "Medicare for All," has faded from public view with the Democratic primaries' submersion. Federalizing Medicaid would be a step in this direction (Huberfeld 2011), though other options exist, such as reinstating the federal match of $100 \%$ for the expansion population.

Second, long-term solutions should address the underinsured - those who have coverage but who avoid care because out-of-pocket costs are too high. Because private insurers require subscribers to pay copayments and deductibles, both of which have been shown to prevent access to care and medications, greater access to private insurance is not the best approach for 
poor populations. Congress could craft a public option, a dominant strategy in current health reform bills, which would bypass states continuing to resist Medicaid expansion and facilitate a new form of public insurance.

Third, the intense connection between health insurance and employment should be revisited. This can be done without creating a single-payer system, such as by lowering the Medicare eligibility age or allowing people to buy into Medicare or Medicaid (HR 1346 2019; Klein 2020). A less dramatic approach would be for Congress to extend premium tax credits for purchasing insurance on an exchange down to $0 \%$ of FPL. This idea may have some hope for bipartisan support, as it was a component of the Better Care Reconciliation Act advanced by the Republican Senate leadership in 2017.

Finally, the most comprehensive long-term solutions would reorient the health reform debate toward achieving health rather than access to health coverage (Jones, Simmons, and Galea 2017). Public health infrastructure must be dramatically strengthened. The social determinants of health should be more central to the health reform conversation -indeed, all policymaking - and not just in ways that place the responsibility on health care delivery systems.

\section{Conclusion}

As we write, the total number of confirmed novel coronavirus cases in the U.S. reached $1,212,123$ and the total number of confirmed deaths was 71,526 (exceeding American deaths from 9/11 and the Vietnam War), with people of color and low socioeconomic status disproportionately affected. Coronavirus has highlighted latent issues, often dormant in a boom economy, that make federalism a complicated and fraught health policy choice. While Americans often resist government intervention, they expect government to respond quickly in a 
time of crisis (Montanaro 2020). Individual and population health cannot respond well to this paradox. Coronavirus does not care about borders or demographics, and pandemic-level preparedness cannot exist without a healthier national population that experiences fewer health disparities. Near-, middle-, and long-term measures are needed to decrease avoidable risks and unnecessary deaths during this pandemic and beyond.

Nicole Huberfeld is professor of health law, ethics, and human rights and professor of law at Boston University. Her scholarship explores the cross section of health law and constitutional law, often addressing health reform (especially Medicaid), federalism, and the spending power. She is author of two health law casebooks and many book chapters and articles, including "What Is Federalism in Healthcare For?" (Stanford Law Review, 2018, with Abbe Gluck), a 5-year study of the federalism dynamics of the implementation of the ACA, and "Federalizing Medicaid" (2011), cited in the first Supreme Court decision on the ACA. nlh@bu.edu

Sarah H. Gordon is assistant professor in the Department of Health Law, Policy, and Management at Boston University School of Public Health. She is a quantitative researcher studying the effects of state policies on insurance coverage and healthcare utilization. In her prior work, she examined disenrollment from Affordable Care Act Marketplaces and compared the effects of public coverage versus subsidized private coverage on costs, quality, and utilization of care. Her broad interests are in state health policy, access to care, and health equity.

David K. Jones is associate professor at Boston University School of Public Health. He is the author of Exchange Politics: Opposing Obamacare in Battleground States(2017). His work has appeared in the New York Times, the Washington Post, and the Wall Street Journal, among others. He has been awarded the Academy-Health Outstanding Dissertation Award and the John D. Thompson Prize for Young Investigators by the Association of University Programs in Health Administration.

\section{References}

Acharya, Avidit, Blackwell, Matthew, and Maya Sen. 2018. Deep Roots. Princeton University Press: Princeton. 
AHR (America's Health Rankings). 2019. "Uninsured.” United Health Foundation. https://www.americashealthrankings.org/explore/annual/measure/HealthInsurance/state/ MS (accessed May 1, 2020).

Almukhtar, Sarah et al. 2020. "Coronavirus in the U.S.: Latest Map and Case Count." New York Times. https://www.nytimes.com/interactive/2020/us/coronavirus-us-cases.html (accessed May 1, 2020).

Campbell, Larrison. 2019. "Half of Mississippi's Rural Hospitals at Risk of Closing, Report Says." Mississippi Today, February 27. https://mississippitoday.org/2019/02/27/half-ofmississippis-rural-hospitals-at-risk-of-closing-report-says/ (accessed May 1, 2020).

CBPP. 2020. "Most States are Using New Flexibility in SNAP to Respond to COVID-19 Challenges." https://www.cbpp.org/research/food-assistance/most-states-are-using-newflexibility-in-snap-to-respond-to-covid-19 (accessed May 1, 2020).

Claxton, Gary et al. 2019. "Employer Health Benefits Annual Survey." Kaiser Family Foundation. http://files.kff.org/attachment/Report-Employer-Health-Benefits-AnnualSurvey-2019 (accessed May 1, 2020).

Fiedler, Matthew and Wilson Powell. 2020. "States Will Need More Fiscal Relief. Policymakers Should Make that Happen Automatically." Brookings. https://www.brookings.edu/blog/usc-brookings-schaeffer-on-healthpolicy/2020/04/02/states-will-need-more-fiscal-relief-policymakers-should-make-thathappen-automatically/ (accessed May 1, 2020).

Ganucheau, Adam. 2018. "Poll: Mississippians Worried about State Economy." Mississippi Today. April 12. https://mississippitoday.org/2018/04/12/nbc-news-survey-monkey-pollmississippians-worried-about-state-economy/?mc_cid=77f2724df8\&mc_eid=df26913b5e (accessed May 1, 2020).

Guth, Madeline , Garfield, Rachel, and Robin Rudowitz. 2020. "The Effects of Medicaid Expansion under the ACA: Updated Findings from a Literature Review. Kaiser Family Foundation." https://www.kff.org/medicaid/report/the-effects-of-medicaid-expansionunder-the-aca-updated-findings-from-a-literature-review (accessed May 1, 2020).

Guzman, Gloria. 2019. "New Data Shows Income Increased in 14 States and 10 of the Largest Metros." US Census Bureau. https://www.census.gov/library/stories/2019/09/us-medianhousehold-income-up-in-2018-from-2017.html (accessed May 1, 2020).

Hensley, Erica. 2018. “'System Doesn't Work for Anybody': Repeat Evictions Take Toll on Tenants Courts and Landlord." Mississippi Today, September 28. https://mississippitoday.org/2018/09/28/system-doesnt-work-for-anybody-repeatevictions-take-toll-on-tenants-justice-courts-andlandlords/?utm_source=Mississippi + Today + Supporters\&utm_campaign=69dfe15d69EMAIL_CAMPAIGN_2019_03_12_09_52\&utm_medium $=$ email\&utm_term $=0$ _ac $1 \mathrm{~d} 8$ 600e-69dfe15d69-168912169\&mc_cid=69dfe15d69\&mc_eid $=$ df26913b5e (accessed May 1, 2020)

H.R. 1346. 2019. "Medicare Buy-In and Health Care Stabilization Act of 2019." https://www.congress.gov/bill/116th-congress/house-bill/1346 (accessed May 1, 2020).

Huberfeld, Nicole. 2011. "Federalizing Medicaid." Journal of Constitutional Law 14, no. 2: 431484.

Forthcoming in Journal of Health Politics, Policy and Law. DOI: 10.1215/03616878-8641493 
Jones, David. 2017. "Health Reform in the South: Re-Tracing Robert Kennedy's Steps in Mississippi and Kentucky." World Medical \& Health Policy 9, no. 2: 225-238.

Jones, David. 2019. "Political Participation in the Least Place in America: Examining the Political Determinants of Health in the Mississippi Delta." Journal of Health Politics, Policy and Law 44, no. 3: 505-531.

Jones, David K., Simmons, Molly, and Sandro Galea. 2017. "Improved Health: A Bipartisan Opportunity to Expand the Scope of Reform." American Journal of Public Health 107, no. 9: 1383-1384.

Klein, Ezra. 2020. "It's Time to Move Past Employer-Based Insurance." Vox, April 9. https:/www.vox.com/2020/4/9/21210353/coronavirus-health-insurance-biden-sandersmedicare-for-all (accessed May 1, 2020).

KFF (Kaiser Family Foundation). 2020a. "Primary Care Health Professional Shortage Areas (HPSAs)." https://www.kff.org/other/state-indicator/primary-care-health-professionalshortage-areas-hpsas (accessed May 1, 2020).

KFF (Kaiser Family Foundation). 2020b. "Medicaid Emergency Authority Tracker: Approved State Actions to Address COVID-19." https://www.kff.org/medicaid/issuebrief/medicaid-emergency-authority-tracker-approved-state-actions-to-address-covid19/\#Table2 (accessed May 1, 2020).

McNichol, Elizabeth, Leachman, Michael, and Joshua Marshall. 2020. "States Need Significantly More Fiscal Relief to Slow the Emerging Deep Recession." CBPP. https://www.cbpp.org/research/state-budget-and-tax/states-need-significantly-morefiscal-relief-to-slow-the-emerging-deep (accessed May 1, 2020).

MS Center for Justice. 2019. "Predatory Lending." https://www.mscenterforjustice.org/ourwork/consumer-protection/predatory-lending (accessed May 1, 2020).

MSDES (MS Department of Economic Security). 2020. "Mississippi Unemployment Rates by County." https://mdes.ms.gov/media/8651/uratesmap.pdf (accessed May 1, 2020).

MS Division of Medicaid. 2019. "Income Limits for Medicaid and CHIP Programs." https://medicaid.ms.gov/medicaid-coverage/who-qualifies-for-coverage/income-limitsfor-medicaid-and-chip-programs/ (accessed May 1, 2020).

MS House Bill 1090. 2017. "Medicaid and Human Services Transparency and Fraud Prevention Act.” http://billstatus.ls.state.ms.us/documents/2017/pdf/HB/1000-1099/HB1090SG.pdf (accessed May 1, 2020).

Montanaro, Domenico. 2020. “Americans Are Generally Skeptical Of Government, But Want It To Intervene In A Crisis.” NPR. https://www.npr.org/2020/04/27/844690526/americansare-generally-skeptical-of-government-but-want-it-to-intervene-in-acr?utm_campaign $=$ KHN $\% 3 \mathrm{~A} \% 20$ Daily $\% 20$ Health $\% 20$ Policy $\% 20$ Report\&utm_source $=\mathrm{h}$ s_email\&utm_medium $=$ email\&utm_content $=87002495 \&$ hsenc $=$ p2ANqtz--mfbIrx16wzLkkryGi1xq1Yv2UMdXjfFc3mAhk-7eakINsZvipq9Y0cLV5kTqTO7NUc36A0iyydh12Z3npIOBsTdLQ\&_hsmi=87002495 (accessed May 1, 2020).

Nchako, Caitlin and Lexin Cai. 2020. "A Closer Look at Who Benefits from SNAP: State-byState Fact Sheets." CBPP. https://www.cbpp.org/research/food-assistance/a-closer-look-

Forthcoming in Journal of Health Politics, Policy and Law. DOI: 10.1215/03616878-8641493 
at-who-benefits-from-snap-state-by-state-fact-sheets\#Mississippi (accessed May 1, 2020).

Pew. 2020. "States Posted Healthy Tax Gains in First Half of Budget Year." https://www.pewtrusts.org/en/research-and-analysis/data-visualizations/2014/fiscal50\#ind0 (accessed May 1, 2020).

PHI (Population Health Institute). 2016a. "Severe Housing Problems." County Health Rankings and Roadmaps.

https://www.countyhealthrankings.org/app/mississippi/2016/measure/factors/136/map (accessed May 1, 2020).

PHI (Population Health Institute). 2016b. "Median Household Income.” County Health Rankings and Roadmaps.

https://www.countyhealthrankings.org/app/mississippi/2016/measure/factors/63/data?sort $=$ sc-2 (accessed May 1, 2020).

PHI (Population Health Institute). 2016c. “\% Non-Hispanic African-American.” County Health Rankings and Roadmaps.

https://www.countyhealthrankings.org/app/mississippi/2016/measure/factors/54/data?sort $=$ desc -3 (accessed May 1, 2020).

PHI (Population Health Institute). 2018. "Food Insecurity." County Health Rankings and Roadmaps.

https://www.countyhealthrankings.org/app/mississippi/2018/measure/factors/139/data?so $\mathrm{rt}=\mathrm{desc}-3$ (accessed May 1, 2020).

Public Law 111-5, sec. 5001, Feb. 17, 2009, https://www.congress.gov/111/plaws/publ5/PLAW111pub15.pdf (accessed May 1, 2020).

Shipan, Charles R., and Craig Volden. 2008. "The Mechanics of Policy Diffusion." American Journal of Political Science 52, no. 4: 840-857.

Smith, Vernon K. et al. 2009. "The Crunch Continues: Medicaid Spending, Coverage and Policy in the Midst of a Recession." Kaiser Family Foundation. https://www.kff.org/wpcontent/uploads/2013/01/7985_es.pdf (accessed May 1, 2020).

US Census Bureau. 2019. "QuickFacts: Mississippi.” https://www.census.gov/quickfacts/MS (accessed May 1, 2020).

Villarosa, Linda. 2020. "Who Lives? Who Dies?: How Covid-19 has revealed the deadly realities of a racially polarized America." New York Times Magazine. May 3: 34-39, 5051.

Wolfe, Anna. 2019. "Waging a Living.” Mississippi Today, May 21. https://mississippitoday.org/2019/05/21/waging-a-living-how-mississippis-a, undant-lowwage-workers-earn-less-today-than-50-yearsago/?utm_source=Mississippi+Today+Supporters\&utm_campaign=b7d7fla94dEMAIL_CAMPAIGN_2019_05_20_08_57\&utm_medium $=$ email\&utm_term $=0$ _ac1d8 600e-b7d7fla94d-168912169\&mc_cid $=$ b7d7f1a94d\&mc_eid $=$ df26913b5e (accessed May 1, 2020).

Wolfe, Anna. 2020a. "Mississippi's record-breaking unemployment claims spike $1700 \%$ in two weeks of COVID-19." Mississippi Today. https://mississippitoday.org/2020/04/02/mississippis-record-breaking-unemployment-

Forthcoming in Journal of Health Politics, Policy and Law. DOI: 10.1215/03616878-8641493 
claims-spike-1700-in-two-weeks-of-covid19/?utm_source=Mississippi+Today+Supporters\&utm_campaign=76ba08deecEMAIL_CAMPAIGN_2019_06_26_02_25_COPY_01\&utm_medium=email\&utm_term $=0 \_2 \mathrm{ac} 1 \mathrm{~d} 8600 \mathrm{e}-76 \mathrm{ba} 08 \mathrm{deec}-168912169 \& \mathrm{mc} \_\mathrm{cid}=76 \mathrm{ba} 08 \mathrm{deec} \& \mathrm{mc}$ eid $=\mathrm{df2} 6913 \mathrm{~b} 5 \mathrm{e}$ (accessed May 1, 2020).

Wolfe, Anna. 2020b. "Connecting the Dots: Players in Massive Welfare Embezzlement Case Got Millions from Taxpayers, but Helped Few." Mississippi Today, February 6. https://mississippitoday.org/2020/02/06/connecting-the-dots-players-in-massive-welfareembezzlement-case-got-millions-from-taxpayers-but-helped-few/ (accessed May 1, 2020).

Zephyrin, Laurie, et al. "COVID-19 More Prevalent, Deadlier in U.S. Counties with Higher Black Populations." Commonwealth Fund, April 23.

https://www.commonwealthfund.org/blog/2020/covid-19-more-prevalent-deadlier-uscounties-higher-black-populations (accessed May 7, 2020).

Forthcoming in Journal of Health Politics, Policy and Law. DOI: 10.1215/03616878-8641493 